\title{
Recycling of pomegranate peel and mandarin peel with ultrasound assisted solvent extraction
}

\author{
Merve Huseyinbas*, Berkay Korkmaz, Selin Yucelen, Afife Guvenc \\ Ankara University, Graduate School of Natural and Applied Science, Chemical Engineering Department, Ankara
}

\begin{abstract}
According to the data of Food and Agriculture Organization, approximately one third of the food produced in the world (1.6 billion tons/year) is lost when it is not reused at the end of consumption. For the recovery and reuse of valuable ingredients (flavonoids, anthocyanins, phenolic acids) in 'Katırbaşı' pomegranate peel and 'Satsuma' type mandarin peel, which are food industry wastes, ultrasound assisted extraction method (UAEM) which is green technology was used. The effects of various solvents and particle size on extraction yield were investigated by applying solvent / solid ratio of $5 \mathrm{ml} / \mathrm{g}$, particle size of $0.5-1 \mathrm{~mm}$ pomegranate peels and $10 \mathrm{~min}$. extraction time for UAEM. The highest efficiency was achieved by using water with $18 \%$. Total phenolic content (TPC) values are $16.55 \mathrm{mg}$ GAE/g dry peel(dp), 14.4 $\mathrm{mg} \mathrm{GAE} / \mathrm{g} \mathrm{dp}, 12.55 \mathrm{mg} \mathrm{GAE} / \mathrm{g} \mathrm{dp}, 10.9 \mathrm{mg} \mathrm{GAE} / \mathrm{g} \mathrm{dp}, 14.45 \mathrm{mg} \mathrm{GAE} / \mathrm{g}$ dp for distilled water, methanol, 50\% methanol-water, ethanol, 70\% ethanol-water solvents, respectively, for $0.5-1$ $\mathrm{mm}$ particle size. TPC was found as $11.75 \mathrm{mg} \mathrm{GAE} / \mathrm{g}$ dp for particle size of $0.25 \mathrm{~mm}$ and below and $17.5 \mathrm{mg} \mathrm{GAE} / \mathrm{g}$ dp for the range of particle size of 1-2 mm using water. Also, similar experiments were made for mandarin peels; TPC and AA (Antioxidant Activity, with DPPH) were determined. The parameters were chosen as different solvent type (water, 100\% ethanol, $80 \%$ ethanol-water, $100 \%$ methanol, 80\% methanol-water), extraction time (10 and $20 \mathrm{~min}$.) and solvent/solid ratio $(10,20 \mathrm{ml} / \mathrm{g}$ ) as well. TPC and AA were found $17.8 \mathrm{mg} \mathrm{GAE} / \mathrm{g} \mathrm{dp}$ and $90 \%$ for $100 \%$ methanol, 10 minutes and $20 \mathrm{ml} / \mathrm{g}$ solvent/solid ratio, respectively. When the ultrasound application time was $20 \mathrm{~min}$, TPC and AA were found $18.24 \mathrm{mg} \mathrm{GAE} / \mathrm{g} \mathrm{dp}$ and 90\% for $20 \mathrm{ml} / \mathrm{g}$ solvent/solid ratio and $80 \%$ methanol, respectively. The highest extraction yield was $19 \%$ using distilled water for $20 \mathrm{~min}, 10 \mathrm{ml} / \mathrm{g}$ solvent/solid ratio. These valuable wastes containing high amount of phenolic compounds could be used to increase nutritional value, extending shelf life, etc. in food, cosmetic and pharmaceutical industries instead of synthetic antioxidants.
\end{abstract}

Keywords: Pomegranate peel, mandarin peel, ultrasound assisted solvent extraction, polyphenol, antioxidants 


\section{Introduction}

Nowadays, considering the side effects of drugs, the idea of using natural supplements to prevent diseases and provide a healthier standard of life is gaining importance day by day instead of using drugs for the treatment of the disease.

Free radicals are formed in the organism during the functioning of normal metabolic pathways or under the influence of various external factors such as environmental agents (pesticides, aromatic hydrocarbons, toxins, solvents etc.), stress, radiation. Free radicals are short-lived, reactive molecules that contain electrons that are not shared in their outer orbitals. Polyphenols have antioxidant activity due to their ability to oxidize easily. Oxidation leads to a decrease in nutritional value and shelf life in food products. Natural antioxidants are used as preservatives in the food industry and they are also important because of their positive effects on human health $[1,2]$.

Extracts from plants; They contain phytochemicals, bioactive compounds, aromatics and color substances. Plant extracts are used in the food, pharmaceutical and cosmetic industries.

Pomegranate peel and mandarin peel emerges as a waste in fruit juice production in the food industry. Polyphenols, which are abundant in pomegranate peel and mandarin peel, are recycled by extraction and there are many studies.

Extraction with traditional methods takes a very long time and huge amounts of solvent are needed. Thanks to the ultrasonic wave assisted extraction, extracts are obtained in a shorter time and with higher efficiency [1].

In this study, it was aimed to investigate the effect of the solvent type, particle size and extraction time parameters on the total phenolic content and antioxidant activity of the phenolic compounds in pomegranate and mandarin peel.

\section{Materials and Method}

Satsuma type mandarines obtained from the research gardens of Republic of Turkey of the Ministry of Agriculture and Forestry, Alata Horticultural Research Institute, and Katırbaşı type pomegranates obtained from Hatay were used. The supplied materials were separated from their peel and dried at room temperature for about 7 days. Dried materials peels were ground in a laboratory mill (Waring products division torrington CT, USA) with a particle size range of $0.25 \mathrm{~mm}-2.00 \mathrm{~mm}$. 
The extraction was performed by means of an ultrasound (Hielscher UP100H, Germany) at a constant frequency of $30 \mathrm{kHz}$. The ultrasound processor was attached to a probe with the diameter of $4 \mathrm{~mm}$. The operation was carried out under the pulsed mode $(0.6 \mathrm{~s}$ on- $0.4 \mathrm{~s}$ off $)$ and constant amplitude level (\%60).

For mandarin peels, the parameters were chosen as different solvent type (water, 100\% ethanol, $80 \%$ ethanol-water, $100 \%$ methanol, $80 \%$ methanol-water), ultrasound application time (10 and $20 \mathrm{~min}$ ) and solvent/solid ratio $(10,20 \mathrm{ml} / \mathrm{g})$. For pomegranate peels, the independent processing variables were solvent type (water, $100 \%$ ethanol, $70 \%$ ethanol-water, $100 \%$ methanol, 50\% methanol-water) and particle size (1-2mm, 0.50mm-1 mm and 0.25mm-below), ultrasound application time $(10 \mathrm{~min})$ and solvent/solid ratio $(5 \mathrm{ml} / \mathrm{g})$ under the constant room temperature $\left(25^{\circ} \mathrm{C}\right)$. A rotary evaporator (Heidolp Laborota 4000$)$ was used to remove solvents from the extracts at $50^{\circ} \mathrm{C}$. Solvent selection was made by considering the studies on each material.

\subsection{Determination of extraction yield (\%)}

Extraction yield (\%) was calculated based on Eq. (1) as also reported by Chemat et al. [1]

Yield $(\%)=\frac{\text { mass of peel extracts }}{\text { mass of peel powder }} \times 100$

\subsection{Determination of total phenolic content (mgGAE/g dry peel)}

The total phenolic contents (TPC) of pomegranate and mandarin peel extracts were determined according to Folin Ciocalteu method [2].

\subsection{DPPH radical scavenging assay}

Antioxidant activity (AA) was determined using DPPH, which is a stable free radical and is widely used to assess the radical scavenging activity of antioxidant components.

The radical scavenging activity of mandarin peel extract was determined using 2,2 Diphenyil1-picrylhydrazyl (DPPH) according to the method described by [3].

The decrease in absorbance was converted to the antioxidant activity (\%) for each concentration of the extracts based on Eq. (2).

$\%$ Antioxidan activity $=\frac{\text { Control absorbance-Sample absorbance }}{\text { Control absorbance }} \times 100$ 


\section{Results and Discussion}

\subsection{Effect of pulsed ultrasound-assisted extraction variables on total phenolic content and antioxidant activity for mandarin peel}

The effects of solvent type, solvent/solid ratio and ultrasound application time (i.e. extraction time) on the total phenolic content and antioxidant activity were investigated. As shown in Table 1, the highest total phenolic content and antioxidant activity was observed for methanol at $10 \mathrm{~min}$ ultrasound application time and $10 \mathrm{ml} / \mathrm{g}$ solvent/solid ratio.

Table 1. Effect of solvent type on TPC and AA (ultrasound application time: $10 \mathrm{~min}$; solvent/solid ratio :10 $\mathrm{ml} / \mathrm{g}$ )

\begin{tabular}{ccc}
\hline Solvent & $\begin{array}{c}\text { Total Phenolic Content } \\
(\mathrm{mgGAE} / \mathrm{g} \text { dry peel })\end{array}$ & $\begin{array}{c}\text { Antioxidant Activity } \\
(\%)\end{array}$ \\
\hline Water & 11.09 & 75 \\
80\% Ethanol & 6.09 & 86 \\
100\% Ethanol & 5.15 & 87 \\
80\% Methanol & 11.80 & 85 \\
100\% Methanol & 13.00 & 89 \\
\hline
\end{tabular}

Table 2. Effect of solvent type on TPC and AA (ultrasound application time: $10 \mathrm{~min}$; solvent/solid ratio :20 ml/g)

\begin{tabular}{ccc}
\hline Solvent & $\begin{array}{c}\text { Total Phenolic Content } \\
(\mathrm{mgGAE} / \mathrm{g} \text { dry peel })\end{array}$ & $\begin{array}{c}\text { Antioxidant Activity } \\
(\%)\end{array}$ \\
\hline Water & 12.2 & 82 \\
80\%Ethanol & 12.4 & 95 \\
$100 \%$ Ethanol & 8.4 & 86 \\
80\%Methanol & 16.4 & 93 \\
100\% Methanol & 17.8 & 90 \\
\hline
\end{tabular}

Table 1 and 2 showed the effect of solvent type on the total phenolic content and antioxidant activity for different solvent/solid ratios. Increased solvent/solid ratio caused an increase in total phenolic content and antioxidant activity. In addition, the increase of solvent/solid ratio leads to excessive swelling of the plant material increasing the contact surface area between the material and the solvent [4]. 
Table 3. Effect of solvent type on TPC and AA (ultrasound application time: $20 \mathrm{~min}$; solvent/solid ratio:10 $\mathrm{ml} / \mathrm{g}$ )

\begin{tabular}{ccc}
\hline Solvent & $\begin{array}{c}\text { Total Phenolic Content } \\
(\mathrm{mgGAE} / \mathrm{g} \text { dry peel })\end{array}$ & $\begin{array}{c}\text { Antioxidant Activity } \\
(\%)\end{array}$ \\
\hline Water & 15.80 & 88 \\
80\% Ethanol & 15.00 & 92 \\
$100 \%$ Ethanol & 5.70 & 81 \\
$80 \%$ Methanol & 9.73 & 92 \\
100\% Methanol & 10.57 & 93 \\
\hline
\end{tabular}

When Table 1 and 3 are observed together, it is seen that there is an increase especially for antioxidant activity. The increase in the total phenolic content was seen mostly in ultrasound assisted extraction with water for $20 \mathrm{~min}$.

Table 4. Effect of solvent type on TPC and AA (ultrasound application time: $20 \mathrm{~min}$; solvent/solid ratio :20 ml/g)

\begin{tabular}{ccc}
\hline Solvent & $\begin{array}{c}\text { Total Phenolic Content } \\
(\mathrm{mgGAE} / \mathrm{g} \text { dry peel })\end{array}$ & $\begin{array}{c}\text { Antioxidant Activity } \\
(\%)\end{array}$ \\
\hline Pure Water & 14.96 & 72 \\
80\% Ethanol & 10.58 & 88 \\
100\% Ethanol & 6.12 & 79 \\
$80 \%$ Methanol & 18.24 & 90 \\
100\% Methanol & 13.08 & 89 \\
\hline
\end{tabular}

According to Table 4, the best result was seen in $80 \%$ methanol, with the ultrasonic application time and solvent/solid ratio doubling.

Higher solvent/solid ratio resulted in great concentration gradient during the diffusion and, in higher phenolic concentration in the extract [5]. A mixture of methanol and water was found more efficient in extracting phenolic matter compared to a mono-component solvent type. The extraction of phenolic components increases with an increase in polarity and a decrease in viscosity, due to their effects on cavitation phenomena. It can be attributed to "like dissolves like" or "polarity-polarity" principles [2, 4].

According to all results, the highest total phenolic content was achieved using $80 \%$ ethanol, 20 $\mathrm{ml} / \mathrm{g}$ solvent to solid ratio and ultrasound application time of $20 \mathrm{~min}$. During pulsed UAE the amount of phenolic matter in mandarin peel extracts increased with the increasing of ultrasound 
application time. Longer extraction time can contribute to disruption of cell walls and better penetration of solvent into cells [4].

Table 5. The extraction yields of the best solvents for different extraction times and solvent/solid ratios

\begin{tabular}{cccc}
\hline Time $(\min )$ & $\begin{array}{c}\text { Solvent/Solid Ratio } \\
(\mathrm{ml} / \mathrm{g})\end{array}$ & Solvent & Yield (\%) \\
\hline 10 & 10 & $100 \%$ Methanol & 6 \\
10 & 20 & $100 \%$ Methanol & 17 \\
20 & 10 & Water & 19 \\
20 & 20 & $80 \%$ Methanol & 17 \\
\hline
\end{tabular}

Extraction yields of the best solvents in all parameters showed at Table 5. Methanol has been found to be a good and effective solvent for ultrasound assisted extraction. The highest extraction yield (17\%) was achieved using $80 \%$ methanol, solvent/solid ratio of $20 \mathrm{ml} / \mathrm{g}$ and ultrasound application time of $20 \mathrm{~min}$.

\subsection{Effect of particle size and solvent type on total phenolic content (TPC) and extraction yield in pulsed ultrasound assisted extraction (PUAE) for pomegranate peel}

The effects of various solvents (water, 100\% methanol, 70\% ethanol, 50\% methanol and 100\% ethanol) and particle size on extraction yield were investigated by applying solvent/solid ratio of $5 \mathrm{ml} / \mathrm{g}$, particle size of $0.5-1 \mathrm{~mm}$ pomegranate peels and 10 minutes ultrasound application time (i.e. extraction time) for pulsed ultrasound assisted extraction. Fig. 1 showed that the highest extraction yield (18\%) was achieved by using water.

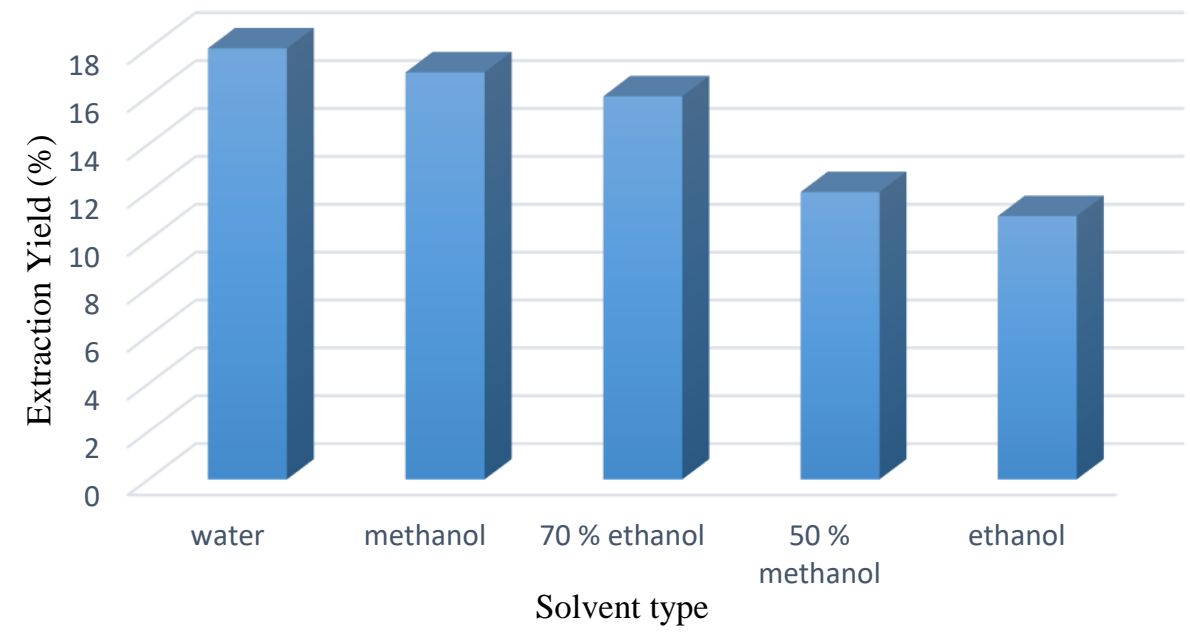

Figure 1. Main effect of various solvent on extraction yield (solvent/solid ratio: $5 \mathrm{ml} / \mathrm{g}$; particle size: $0.5-1 \mathrm{~mm}$; extraction time: $10 \mathrm{~min}$.) 


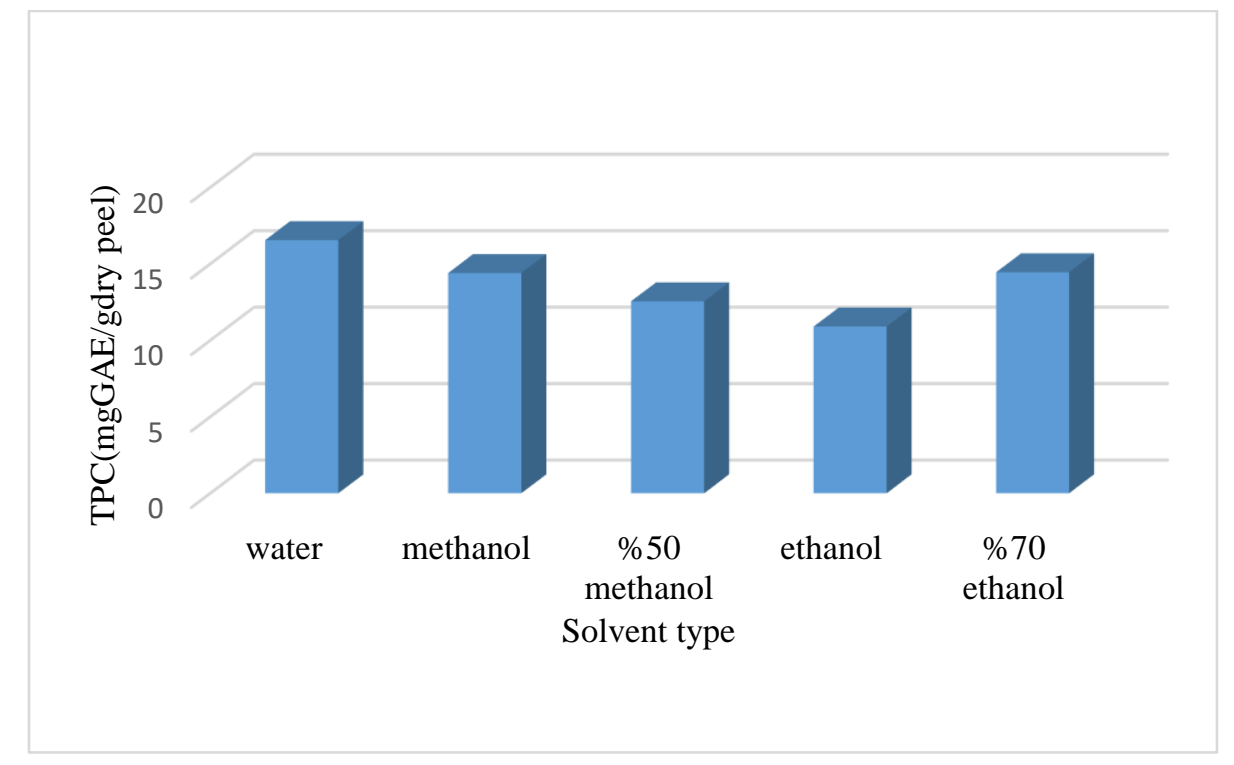

Figure 2. Main effect of solvent type on total phenolic content (solvent/solid ratio: $5 \mathrm{ml} / \mathrm{g}$; particle size: $0.5-1 \mathrm{~mm}$; extraction time: $10 \mathrm{~min}$.)

Fig. 2 presents the effect of various solvent on total phenolic content. The total phenolic content in pomegranate peel extracts obtained using ultrasound assisted extraction varied from 10.9 to $16.55 \mathrm{mg} \mathrm{GAE} / \mathrm{g}$ dry peel.

According to these results, the highest content of phenolic matter was achieved using water. Water is food-grade solvent for green extraction techniques. Water seems the greenest solvent, being nontoxic, noncorrosive, non-flammable, environmentally benign, naturally abundant, and available at low cost $[2,5,6]$.

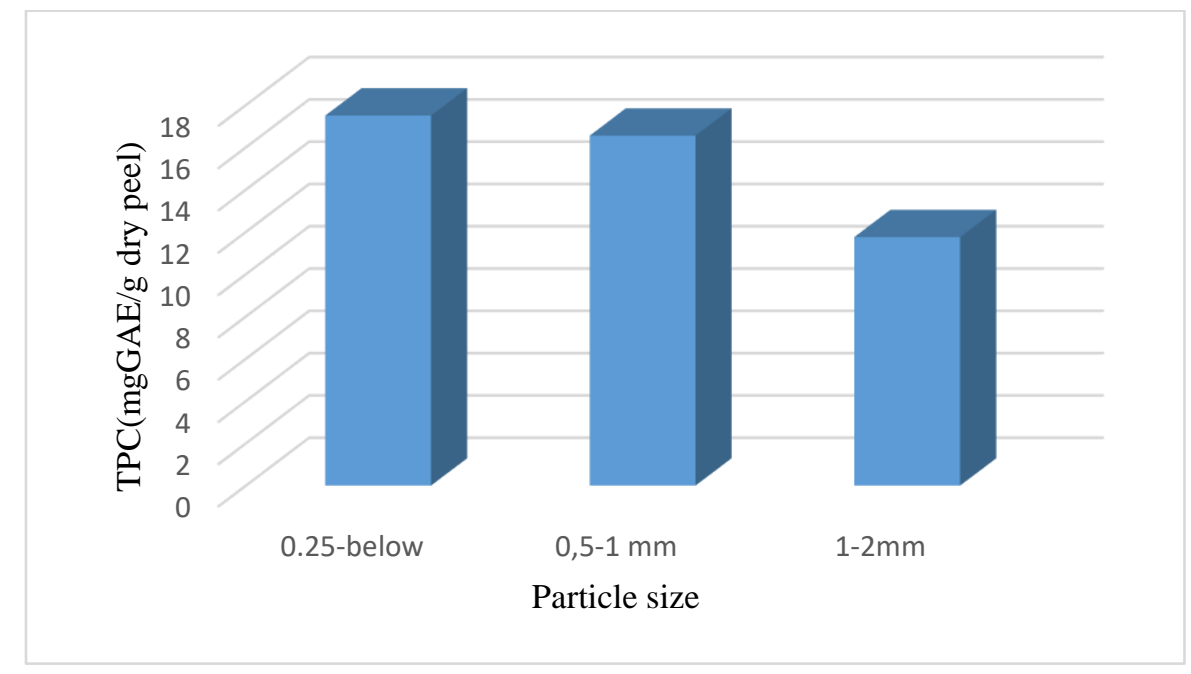

Figure 3. Main effect of particle size on total phenolic content (TPC) (solvent/solid ratio: $5 \mathrm{ml} / \mathrm{g}$; extraction time: $10 \mathrm{~min}$; solvent: water) 
Pomegranate peel powder was passed through three various size sieves (pore sizes of 1-2mm, $0.5-1 \mathrm{~mm}$ and $0.25 \mathrm{~mm}$-below). The results showed that smaller particle size increases the total phenolic content over a 10 min extraction time with water at room temperature and solvent/solid ratio $5 \mathrm{ml} / \mathrm{g}$. The increase of the total phenolic content for the small particles is owing to larger surface area per mass unit $[5,7]$.

\section{Conclusions}

TPC and AA were found $18.24 \mathrm{mg} \mathrm{GAE} / \mathrm{g}$ dp and $90 \%$ for solvent/solid ratio of 20 $\mathrm{ml} / \mathrm{g}, 80 \%$ methanol and $20 \mathrm{~min}$ ultrasound application time for mandarin peels, respectively. The highest extraction yield was 19\% for mandarin peels using water for $20 \mathrm{~min}$, solvent/solid ratio of $10 \mathrm{ml} / \mathrm{g}$. The total phenolic content in pomegranate peel extracts obtained using ultrasound assisted extraction varied from 10.9 to $16.55 \mathrm{mg} \mathrm{GAE} / \mathrm{g}$ dry peel. According to this study, PUAE can be considered as a high-efficiency, safe technique which reduce the extraction time and energy consumption. It is important for human health to use mandarin and pomegranate peels extracts instead of synthetic antioxidants such as BHA (butylated hydroxyanisole), BTA (butylated hydroxytoluene).

\section{References}

[1] Chemat F, Huma, Z, Khan, M. K. Applications of ultrasound in food technology: Processing, preservation and extraction. Ultrasonics Sonochemistry 2011;18:835-813.

[2] Kaderides K, Goula A, Adamopoulos K. A process for turning pomegranate peels into a valuable food ingredient using ultrasound-assisted extraction and encapsulation. Innovative Food Science and Emerging Technologies 2015;31:215-204.

[3] Vural, N. Development of a new methodology for the extraction and analysis of secoiridoid structured polyphenols from Olea europaea L. leaves. Ph.D. Thesis. Ankara University Graduate School of Natural and Applied Sciences Department of Chemistry 2017.

[4] Kaderides K, Papaoikonomou L, Serafim M, Goula A. Microwave-assisted extraction of phenolics from pomegranate peels: Optimization, kinetics, and comparison with ultrasounds extraction. Chemical Engineering \& Processing: Process Intensification 2019;137:11-1.

[5] Tabaraki R, Heidarizadi E, A. Benvidi, Optimization of ultrasonic-assisted extraction of pomegranate (Punica granatum L.) peel antioxidants by response surface methodology. Sep. Purif. Technol. 2012;98:23-16.

[6] Goula A M. Ultrasound-assisted extraction of pomegranate seed oil. Kinetic modeling. Journal of Food Engineering 2013;117:498-492. 
[7] Kazemi M, Karim R, Mirhosseini H, A A Hamid. Optimization of pulsed ultrasonicassisted technique for extraction of phenolics from pomegranate peel of Malas variety: punicalagin and hydroxybenzoic acids. Food Chem. 2016;206:166-156. 